\title{
SYSTOLIC MURMURS IN CHILDREN
}

\section{A SURVEY OF 240 CASES}

\author{
BY \\ W. MAINZER, R. PINCOVICI and G. HEYMANN \\ From the Western Galilee District of Kupat-Holim, Workers' Sick Fund of Israel
}

(RECEIVED FOR PUBLICATION AUGUST 27, 1958)

The general practitioner has to deal almost daily in his work with the problem of systolic murmurs. He finds such murmurs often in apparently healthy children during a routine check and is then confronted by the question whether to consider these murmurs as of no importance, or to investigate further.

There exists a wide discrepancy among publications on the incidence of systolic murmurs in children in general, the percentage varying from $20 \%$ to more than $90 \%$ (Lessof and Brigden, 1957). Also on the prevalence of what are termed 'innocent' systolic murmurs, Fogel (1957) quotes a range of $8 \%$ to $86 \cdot 6 \%$ from various studies.

In order to throw further light on the problem the authors have surveyed the child population of 13 rural settlements and two educational institutions in the Haifa area with regard to the finding of systolic cardiac murmurs.

\section{Material and Methods}

The material consists of all cases in which systolic murmurs were found among a total of 2,035 children up to the age of 15 years during the year 1957. Each child with a systolic murmur was investigated with regard to history, physical examination, fluoroscopic, electrocardiographic and related laboratory findings. In all cases blood counts were made in order to exclude anaemia as the cause of a systolic murmur, and sedimentation rates were determined in a search for signs of rheumatic fever or other active processes. To narrow down the margin of subjective error in auscultation, each child was examined by all three investigators. From the results obtained, a survey was made of the incidence and clinical significance of the murmurs heard, considering also sex, age, familial occurrence, occurrence among siblings, and ethnic origin. The children were divided into three age groups: from birth to 5 years, from 5 to 10 years, and from 10 to 15 years. As to their ethnic origin, three sections of the population were distinguished: (1) children of western origin, whose parents came from Europe or NorthAmerica; (2) children of Mediterranean origin, including Greece, Turkey, North-Africa and also Iraq, though the latter does not border immediately on the Mediterranean Sea; and (3) children from India.

Concerning their clinical significance, the murmurs were classified into four types: (1) innocent murmurs; (2) murmurs indicating possible heart disease; (3) murmurs indicating probable heart disease; and (4) organic murmurs in heart disease. The following standards were applied:

(1) Innocent Murmurs. Murmurs in children who did not show any signs of heart disease, either with regard to history, or to physical, laboratory, fluoroscopic or electrocardiographic findings. Wells (1957) writes: 'The decision that a systolic murmur is innocent depends not only on the character of the murmur itself, but also on the absence of any evidence of organic heart disease.'

(2) Possible Heart Disease. Murmurs with signs referable to heart disease but not conclusive of structural changes, such as, for instance, an incomplete right bundle branch block in the electrocardiographic pattern, or a slight prominence of the pulmonary conus silhouette.

(3) Probable Heart Disease. Murmurs in children with pathological evidence referable to structural changes at the heart, where, however, diagnosis of cardiac disease was still uncertain. Within this category were counted fluoroscopic or electro- 
cardiographic evidence of heart hypertrophy, and also left axis shift, which, according to Katz (1949), is not a normal finding in children. A combination of an incomplete right bundle branch block with a prominent pulmonary conus, too, was considered as probably due to heart disease (atrial septal defect) (Wagner and Graham, 1957).

(4) Heart Disease. Murmurs in children, where a definite diagnosis of heart disease could be made according to accepted standards.

The quality of the murmurs was defined with relation to intensity, continuity, and, location according to the point of maximum audibility. To indicate the intensity of systolic murmurs, Luisada (1954) recommends the six gradations of Levine. For practical purposes, however, the authors of this paper found it sufficient to use only the three grades of 'faint', 'moderate', and 'loud', as accepted by the Criteria Committee of the New York Heart Association (1955), thereby disregarding the finer distinctions of 'very faint' and 'very loud', which have been added in the latest edition of the nomenclature. This is also in accordance with the opinion of Leopold (1957), quoting Levine and Harvey, that the system of six gradations, when used by different clinicians, may, anyhow, differ by one gradation. When the continuity of the murmurs was considered, a distinction was made between 'constant' and 'inconstant'. Murmurs which could always be heard, regardless of the posture of the patient or of time, were called 'constant', while the term 'inconstant' was given to murmurs which disappeared with a change in posture or could be heard only occasionally during the course of several weeks.

\section{Results}

Among 2,035 children examined 240 cases of systolic murmurs were found, i.e. an incidence of $11 \cdot 8 \%$ (Table 1 ).

TABLE 1

INCIDENCE ACCORDING TO AGE.

\begin{tabular}{|c|c|c|c|c|c|}
\hline \multicolumn{2}{|c|}{$0-5$ years } & \multicolumn{2}{|c|}{$5-10$ years } & \multicolumn{2}{|c|}{$10-15$ years } \\
\hline (No.) & $(\%)$ & ${ }_{(\text {No. })}{ }^{C}$ & $(\%)$ & (No.) & $(\%)$ \\
\hline 61 & 30 & 106 & 51 & 39 & 19 \\
\hline
\end{tabular}

In this comparison the children of the two educational institutions have not been taken into consideration, as they were only of one age group, namely 10 to 15 years.

A graphic representation of the age-incidence of systolic murmurs shows that the percentage increases from early childhood until it suddenly reaches its peak after the age of 5. It remains highest at the age group from 5 to 10 years and then decreases again towards the age of 15 (Fig. 1).

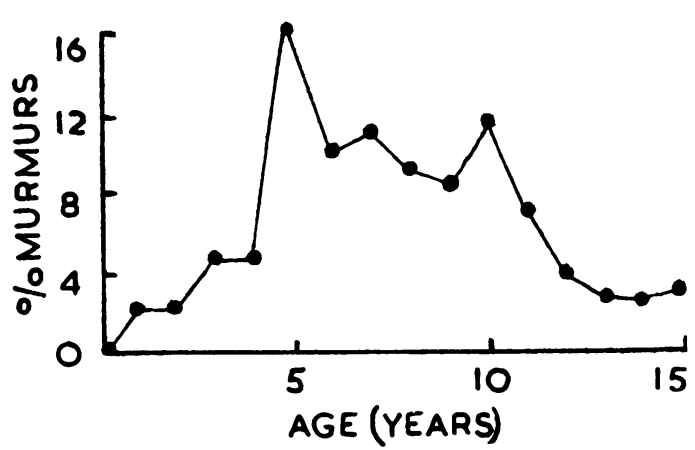

Fig. 1.-Age incidence of systolic murmurs.

More male children were found to have systolic murmurs $(56 \%)$ than females $(44 \%)$, this proportion remaining approximately the same at all age groups (Table 2).

TABLE 2

INCIDENCE OF SYSTOLIC MURMURS IN RELATION TO SEX

\begin{tabular}{l|c|c|c|c|c|c|c|c}
\hline & \multicolumn{2}{|c|}{$0-5$ years } & $5-10$ years & $10-15$ years & \multicolumn{2}{|c}{ Total } \\
\cline { 2 - 4 } & M. & F. & M. & F. & M. & F. & M. & F. \\
\hline $\begin{array}{l}\text { Cases } \\
\text { (No.) }\end{array}$ & 33 & 28 & 59 & 47 & 34 & 25 & 126 & 100 \\
\hline$(\%)$ & 54 & 46 & 56 & 44 & 57 & 43 & 56 & 44 \\
\hline
\end{tabular}

In this compilation the results of one boarding school, at which only boys are received, had, of course, to be omitted. In the course of the analysis of the results in the 13 settlements an interesting fact was encountered, namely that $40 \%$ of all

TABLE 3

FAMILIAL OCCURRENCE OF SYSTOLIC MURMURS

\begin{tabular}{c|c|c}
\hline $\begin{array}{c}\text { Murmurs } \\
\text { (Total no.) }\end{array}$ & (No.) $^{\text {Familial Cases }}$ & $(\%)$ \\
\hline 206 & 83 & 40 \\
\hline
\end{tabular}

systolic murmurs occurred among siblings, i.e. among two or more children of the same parents (Table 3).

Among ethnic groups, the Mediterranean had the highest incidence $(13 \%)$ though only slightly higher 
TABLE 4

INCIDENCE WITH REGARD TO ETHNIC ORIGIN

\begin{tabular}{|c|c|c|c|}
\hline & $\begin{array}{c}\text { Children } \\
\text { (No.) }\end{array}$ & $\begin{array}{l}\text { Systolic } \\
\text { (No.) }\end{array}$ & $\underset{(\%)}{\text { Murmurs }}$ \\
\hline Western .. & 986 & 113 & $11 \cdot 5$ \\
\hline Mediterranean & 898 & 115 & 13 \\
\hline India & 151 & 12 & 8 \\
\hline
\end{tabular}

than the Western with $11.5 \%$, while children from India had the lowest rate with $8 \%$ (Table 4 ).

Clinical Significance. Of all systolic murmurs $64 \cdot 2 \%$ were innocent and in only $3 \cdot 3 \%$ of children with systolic murmurs could a definite diagnosis of heart disease be established. About one-third of all murmurs could not be regarded outright as innocent, but many of these showed only slight pathological results after further investigations, while in about $13 \%$ there was still doubt as to the diagnosis in spite of significant clinical signs (see Table 5).

TABLE 5

INCIDENCE OF SYSTOLIC MURMURS WITH REGARD TO CLINICAL SIGNIFICANCE

\begin{tabular}{|c|c|c|c|c|c|c|c|}
\hline \multicolumn{2}{|c|}{$\begin{array}{c}\text { I } \\
\text { Innocent } \\
\text { Murmurs }\end{array}$} & \multicolumn{2}{|c|}{$\begin{array}{c}\text { II } \\
\text { Possible } \\
\text { Heart Disease }\end{array}$} & \multicolumn{2}{|c|}{$\begin{array}{c}\text { III } \\
\text { Probable } \\
\text { Heart Disease }\end{array}$} & \multicolumn{2}{|c|}{$\begin{array}{c}\text { IV } \\
\text { Heart } \\
\text { Disease }\end{array}$} \\
\hline (No.) & $(\%)$ & (No.) & $(\%)$ & (No.) & $(\%)$ & (No.) & $(\%)$ \\
\hline 154 & $64 \cdot 2$ & 47 & $19 \cdot 5$ & 31 & 13 & 8 & $3 \cdot 3$ \\
\hline
\end{tabular}

A survey of the electrocardiographic findings (Table 6) showed a normal E.C.G. in almost $78 \%$ of the children with systolic murmurs.

TABLE 6

MAIN ELECTROCARDIOGRAPHIC PATTERNS

\begin{tabular}{|c|c|c|c|c|c|c|c|c|c|}
\hline \multicolumn{2}{|c|}{$\begin{array}{c}\text { Normal } \\
\text { E.C.G. }\end{array}$} & \multicolumn{2}{|c|}{$\begin{array}{l}\text { Left Axis } \\
\text { Deviation }\end{array}$} & \multicolumn{2}{|c|}{$\begin{array}{c}\text { Incomplete } \\
\text { Right } \\
\text { Bundle } \\
\text { Branch } \\
\text { Block }\end{array}$} & \multicolumn{2}{|c|}{$\begin{array}{l}\text { Left } \\
\text { Ventricular } \\
\text { Hyper- } \\
\text { trophy }\end{array}$} & \multicolumn{2}{|c|}{$\begin{array}{l}\text { Right } \\
\text { Ventricular } \\
\text { Hyper- } \\
\text { trophy }\end{array}$} \\
\hline (No.) & $(\%)$ & (No.) & $(\%)$ & (No.) & $(\%)$ & (No.) & $(\%)$ & (No.) & $(\%)$ \\
\hline 186 & $77 \cdot 5$ & 14 & 6 & 30 & $12 \cdot 5$ & 8 & 3 & 2 & 1 \\
\hline
\end{tabular}

The results of fluoroscopy are shown in Table 7. Since sometimes more than one change could be found in the same child there are more fluoroscopic findings than there were cases of systolic murmur.

As to the location of systolic murmurs, five different sites of maximum audibility could be discerned in this investigation: (1) parasternal murmurs, which were located at the third or fourth
TABLE 7

FLUOROSCOPIC FINDINGS

\begin{tabular}{|c|c|c|c|c|c|c|c|}
\hline \multicolumn{2}{|c|}{ Normal } & \multicolumn{2}{|c|}{$\begin{array}{l}\text { Pulmonary } \\
\text { Prominence }\end{array}$} & \multicolumn{2}{|c|}{$\begin{array}{c}\text { Aortic } \\
\text { Prominence }\end{array}$} & \multicolumn{2}{|c|}{$\begin{array}{c}\text { Mitral } \\
\text { Configuration }\end{array}$} \\
\hline (No.) & $(\%)$ & (No.) & $(\%)$ & (No.) & $(\%)$ & (No.) & $(\%)$ \\
\hline 201 & 84 & 19 & 8 & 3 & $1 \cdot 2$ & 3 & $1 \cdot 2$ \\
\hline \multicolumn{2}{|c|}{$\begin{array}{c}\text { Aortic } \\
\text { Configuration }\end{array}$} & \multicolumn{2}{|c|}{$\begin{array}{c}\text { Left } \\
\text { Ventricular } \\
\text { Hypertrophy }\end{array}$} & \multicolumn{2}{|c|}{$\begin{array}{c}\text { Right } \\
\text { Ventricular } \\
\text { Hypertrophy }\end{array}$} & \multicolumn{2}{|c|}{$\begin{array}{c}\text { Global } \\
\text { Hypertrophy }\end{array}$} \\
\hline (No.) & $(\%)$ & (No.) & $(\%)$ & (No.) & $(\%)$ & (No.) & $(\%)$ \\
\hline 2 & 0.8 & 10 & 4 & 8 & $3 \cdot 4$ & 3 & $1 \cdot 2$ \\
\hline
\end{tabular}

thoracic interspace at the left sternal border ; (2) murmurs heard at the so-called 'Erb's point', that is at the third or fourth left interspace, midway between the lateral margin of the sternum and the axillary line, also known as 'secondary aortic area' (Pullen, 1945); (3) murmurs heard over the apex; (4) pulmonic murmurs; and (5) aortic murmurs.

From Table 8 it can be seen that by far the greatest number of systolic murmurs were parasternal $(77 \%$ of the total and $80 \%$ of all innocent murmurs). Then followed the precordial murmurs at Erb's point and the apical murmurs with $10 \%$ and $9 \%$ respectively. Pulmonic murmurs were only about $4 \%$, and only one case of a systolic murmur over the aortic valve was found, which, incidentally proved to be innocent.

Table 8 also represents the results as to intensity of the murmurs. Most of the murmurs were faint or moderate and only a comparatively small number of loud murmurs were heard (about $4 \%$ ). However, among the group of heart diseases proper (Table 8e) the percentage of loud murmurs was $25 \%$.

The following conditions were distinguished among the eight cases of definite heart disease:

$$
\begin{array}{lll}
\multicolumn{1}{c}{\text { Diagnosis }} & \multicolumn{2}{c}{\text { No. of Cases }} \\
\text { Rheumatic heart disease } & \ldots & 4 \\
\text { Mitral insufficiency } & \ldots & 3 \\
\text { Patent ductus arteriosus } & \text {. } & 1
\end{array}
$$

Most of the murmurs were constant. Only 19 inconstant murmurs were registered $(8 \%)$. Eleven of these were innocent murmurs, four indicated possible heart disease, two probable heart disease, and in two cases of heart disease there were also inconstant murmurs (Table 9). As to their location, 12 of the inconstant murmurs were parasternal, four could be heard at Erb's point and three were pulmonic in location. Most of them were faint, one was moderate and one was loud (Table 10). 
TABLE 8

QUALITY OF MURMURS IN RELATION TO INTENSITY AND SITE OF MAXIMAL AUDIBILITY

(a) TOTAL NUMBER OF SYSTOLIC MURMURS

\begin{tabular}{|c|c|c|c|c|c|c|c|c|}
\hline & \multicolumn{2}{|c|}{ Faint } & \multicolumn{2}{|c|}{ Moderate } & \multicolumn{2}{|c|}{ Loud } & \multicolumn{2}{|c|}{ Total } \\
\hline & (No.) & $(\%)$ & (No.) & $(\%)$ & (No.) & $(\%)$ & (No.) & $(\%)$ \\
\hline $\begin{array}{l}\text { Para- } \\
\text { sternal }\end{array}$ & 99 & $41 \cdot 1$ & 83 & $35 \cdot 1$ & 2 & $0 \cdot 8$ & 184 & 77 \\
\hline $\begin{array}{c}\text { Erb's } \\
\text { point }\end{array}$ & 15 & $6 \cdot 3$ & 8 & $3 \cdot 2$ & 2 & 0.8 & 25 & 10 \\
\hline Apex & 3 & $1 \cdot 2$ & 15 & $6 \cdot 3$ & 3 & $1 \cdot 2$ & 21 & 9 \\
\hline$\overline{\text { Pulmonic }}$ & 6 & $2 \cdot 4$ & 1 & 0.4 & 2 & $0 \cdot 8$ & 9 & $3 \cdot 6$ \\
\hline Aorta & & & & & 1 & 0.4 & 1 & 0.4 \\
\hline$\overline{\text { Total } \quad . .}$ & 123 & 51 & 107 & 45 & 10 & 4 & 240 & 100 \\
\hline
\end{tabular}

(b) INNOCENT MURMURS

\begin{tabular}{|c|c|c|c|c|c|c|c|c|}
\hline & \multicolumn{2}{|c|}{ Faint } & \multicolumn{2}{|c|}{ Moderate } & \multicolumn{2}{|c|}{ Loud } & \multicolumn{2}{|c|}{ Total } \\
\hline & (No.) & $(\%)$ & (No.) & $(\%)$ & (No.) & $(\%)$ & (No.) & $(\%)$ \\
\hline $\begin{array}{l}\text { Para- } \\
\text { sternal }\end{array}$ & 65 & 42 & 57 & $37 \cdot 3$ & 1 & 0.7 & 123 & 80 \\
\hline $\begin{array}{c}\begin{array}{c}\text { Erb's } \\
\text { point }\end{array} \\
\end{array}$ & 6 & 4 & 5 & $3 \cdot 3$ & 1 & 0.7 & 13 & 8 \\
\hline Apex .. & 2 & $1 \cdot 4$ & 9 & $5 \cdot 2$ & 1 & 0.7 & 12 & $7 \cdot 3$ \\
\hline Pulmonic & 4 & $2 \cdot 6$ & 1 & $0 \cdot 7$ & 1 & $0 \cdot 7$ & 6 & 4 \\
\hline Aorta & & & & & 1 & 0.7 & 1 & 0.7 \\
\hline Total & 77 & 50 & 72 & $46 \cdot 5$ & 5 & $3 \cdot 5$ & 154 & 100 \\
\hline
\end{tabular}

(c) POSSIBLE HEART DISEASE

\begin{tabular}{c|c|c|c|c|c|c|c|c}
\hline & Fo.) & $(\%)$ & $($ No. $)$ & $(\%)$ & (No.) & $(\%)$ & $($ No. $)$ & $(\%)$ \\
\hline $\begin{array}{c}\text { Para- } \\
\text { sternal }\end{array}$ & 20 & 42 & 15 & 32 & & & 35 & 74 \\
\hline $\begin{array}{c}\text { Erb's } \\
\text { point }\end{array}$ & 5 & $10 \cdot 5$ & 1 & $2 \cdot 5$ & & & 6 & 13 \\
\hline \begin{tabular}{c} 
Apex .. \\
\hline Pulmonic
\end{tabular} & 1 & $2 \cdot 5$ & 4 & 8 & & & 4 & 8 \\
\hline Total .. & 26 & 55 & 20 & $42 \cdot 5$ & 1 & $2 \cdot 5$ & 47 & 100 \\
\hline
\end{tabular}

(d) PROBABle HEART DISEASE

\begin{tabular}{|c|c|c|c|c|c|c|c|c|}
\hline & \multicolumn{2}{|c|}{ Faint } & \multicolumn{2}{|c|}{ Moderate } & \multicolumn{2}{|c|}{ Loud } & \multicolumn{2}{|c|}{ Total } \\
\hline & (No.) & $(\%)$ & (No.) & $(\%)$ & (No.) & $(\%)$ & (No.) & $(\%)$ \\
\hline $\begin{array}{l}\text { Para- } \\
\text { sternal }\end{array}$ & 11 & 36 & 10 & 32 & 1 & 3 & 22 & 71 \\
\hline $\begin{array}{c}\begin{array}{c}\text { Erb's } \\
\text { point }\end{array} \\
\end{array}$ & 3 & 10 & 2 & 7 & 1 & 3 & 6 & 20 \\
\hline Apex .. & 1 & 3 & 1 & 3 & & & 2 & 6 \\
\hline Pulmonic & 1 & 3 & & & & & 1 & 3 \\
\hline Total .. & 16 & 52 & 13 & 42 & 2 & 6 & 31 & 100 \\
\hline
\end{tabular}

(e) HEART DISEASE.

\begin{tabular}{|c|c|c|c|c|c|c|c|c|}
\hline & \multicolumn{2}{|c|}{ Faint } & \multicolumn{2}{|c|}{ Moderate } & \multicolumn{2}{|c|}{ Loud } & \multicolumn{2}{|c|}{ Total } \\
\hline & (No.) & $(\%)$ & (No.) & $(\%)$ & $\overline{\text { (No.) }}$ & $(\%)$ & (No.) & $(\%)$ \\
\hline $\begin{array}{l}\text { Para- } \\
\text { sternal }\end{array}$ & 3 & $37 \cdot 5$ & 1 & $12 \cdot 5$ & & & 4 & 50 \\
\hline Apex $\ldots$ & & & 1 & $12 \cdot 5$ & 2 & 25 & 3 & $37 \cdot 5$ \\
\hline $\begin{array}{l}\text { Erb's } \\
\text { point }\end{array}$ & 1 & $12 \cdot 5$ & & & & & 1 & $12 \cdot 5$ \\
\hline Total & 4 & 50 & 2 & 25 & 2 & 25 & 8 & 100 \\
\hline
\end{tabular}

TABLE 9

INCONSTANT MURMURS WITH RELATION TO CLINICAL SIGNIFICANCE

\begin{tabular}{|c|c|c|c|c|c|}
\hline & & Faint & Moderate & Loud & Total \\
\hline Innocent $\quad .$. & 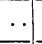 & 10 & & 1 & 11 \\
\hline Possible heart disease & $\ldots$ & 3 & & 1 & 4 \\
\hline Probable heart disease & $\cdots$ & 1 & 1 & & 2 \\
\hline Heart disease & $\cdots$ & 2 & & & 2 \\
\hline Total & $\cdots$ & 16 & 1 & 2 & 19 \\
\hline
\end{tabular}

TABLE 10

INCONSTANT MURMURS, LOCATION AND INTENSITY

\begin{tabular}{|c|c|c|c|c|c|c|}
\hline & & & Faint & Moderate & Loud & Total \\
\hline Parasternal & $\ldots$ &.. & 11 & 1 & & 12 \\
\hline Erb's point &. & 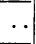 & 3 & 1 & & 4 \\
\hline Pulmonic & $\cdots$ & $\cdots$ & 2 & & 1 & 3 \\
\hline Total & . & $\ldots$ & 16 & 2 & 1 & 19 \\
\hline
\end{tabular}

\section{Discussion}

The incidence of $11.8 \%$ systolic murmurs in this survey is relatively low compared to the incidence in most other similar reports, in which it varied from $20 \%$ to over $90 \%$. However, Szabo and Ross (1957), who investigated the occurrence of heart diseases among school children of the three major cities of Israel, were struck by the comparatively low incidence, especially of innocent murmurs, in this country; they give a rate of $9 \%$ for Haifa. Nevertheless, the age distribution of systolic murmurs corresponds with that found by other authors. The diagram of age-incidence (Fig. 1) follows in principle that given by Epstein (1948), the difference being not the relative incidence at the various age groups, but the absolute numbers, which Epstein found considerably higher. A new fact, of which we found 
no mention in the literature, is the high percentage of systolic murmurs among siblings. Though only children up to the age of 15 years have been taken into consideration, many other cases are known to the authors in which at least one parent, or another brother or sister above the age group investigated, had a systolic murmur. This would put the familial occurrence of systolic murmurs even higher than the $40 \%$ reported. It appears, therefore, that a familial factor is involved in the problem of systolic murmurs. The nature of such a factor is not known. A possible explanation, in accordance with the theory that innocent murmurs arise from eddy currents caused by a difference in the size of the outlet from the ventricles into the great vessels, would be that the individuals of a family have a similar anatomical cardiac structure.

The question of so-called 'functional', 'accidental', 'haemic' or 'innocent' murmurs has been much discussed among clinicians. The authors have accepted the term 'innocent', originally coined by Evans (1947), generally recommended in recent publications and also adopted by the American (New York) Heart Association (1955). This investigation confirmed the conception that there is no physical criterion for an 'innocent' murmur, with regard either to quality or location. The incidence of innocent murmurs in this survey was $64 \cdot 2 \%$ of all systolic murmurs. This coincides approximately with the percentage by Fogel (1957) of $60 \cdot 4 \%$.

The group classified as 'possible heart disease' comprised $19 \cdot 5 \%$ of all cases with systolic murmurs. It included those with only slightly abnormal findings on further investigation.

The group of 'probable heart diseases' comprises children with pathological signs referable to structural changes in the heart, but in whom special investigations like angiocardiography or heart catheterisation were not undertaken either because of their general well-being, or because the risks were not considered justifiable. The incidence of these cases was $13 \%$. Systolic murmurs in children with diagnosed heart diseases constituted $3 \cdot 3 \%$. Altogether the three groups of 'not innocent' murmurs represented $35 \cdot 8 \%$.

The great importance of the electrocardiographic and fluoroscopic investigations (see Tables 6 and 7) in the differentiation between innocent and not innocent murmurs needs to be especially emphasized.

Most of the recent publications agree that innocent systolic murmurs are loudest at the left sternal border in the third and fourth intercostal spaces (Rhodes, 1955; Stuckey, 1955; Fogel, 1957). The authors can verify this in the present paper not only for innocent murmurs, but for all systolic murmurs (Table 8). Of the innocent murmurs the site of maximal intensity was parasternal (at the left sternal border in the third or fourth intercostal space) in 123 out of 154 cases, that is $80 \%$; Fogel (1957) reports $76 \%$. Among the systolic murmurs indicating possible heart disease $74 \%$ were parasternal, of the murmurs of probable heart disease $71 \%$, and of the murmurs in patients with definite heart disease the parasternal location of the murmurs was still preponderant, though its proportion was lower $(50 \%)$. From these facts it is evident that no conclusion can be drawn from the parasternal location of a systolic murmur regarding either its nature or its clinical significance. The same holds true for the other sites of maximal intensity as can be seen from Table 8 .

Similarly, the intensity itself was not of diagnostic significance. In all four groups (Table 8) most of the systolic murmurs were faint in intensity $(50 \%$ and $55 \%$ ). A lesser, but still considerable, number of murmurs was moderate. In the first three groups there was only a comparatively small number of loud murmurs (from $3.5 \%$ to $6 \%$ ), but in the fourth group of murmurs, representing structural changes in the heart or heart disease, the number of loud murmurs equalled those of moderate intensity. Blake and Goodale (1957) draw attention to the danger of drawing conclusions from the intensity of a murmur, in view of the loud systolic murmur that can emanate from a small, insignificant ventricular septal defect and the very faint murmur of pulmonary atresia.

No significance could be attached to the constancy or inconstancy of a murmur. Tables 9 and 10 show that the inconstant murmurs comprised only a small number $(8 \%)$ of all systolic murmurs and were present in all four groups in about equal proportions. There was no relation, either, between inconstancy and location of the murmur.

\section{Summary}

Among 2,035 children up to the age of 15 years, examined during the year 1957, 240 were found to have systolic murmurs, that is $11.8 \%$. The incidence was highest in the age group from 5 to 10 years. More male children had murmurs than females, the proportion remaining approximately the same in all age groups. Forty per cent of all murmurs occurred among siblings, but more cases were known to the investigators, amongst the parents or older siblings, which puts the familial incidence even higher. The hypothesis is advanced that perhaps particular identical anatomical construction of the ventricular outlet among members of 
the same family may be responsible for this phenomenon.

The highest proportion of systolic murmurs were found among the so-called Mediterranean group, followed by the children of Western origin, whilst the lowest percentage was discovered among the children from India.

Out of 240 systolic murmurs, $64 \cdot 2 \%$ were innocent and $35.5 \%$ were considered to be pathological. However, only in eight cases could a definite diagnosis of heart disease be established; the rest showed either only minor pathological findings as a result of further investigations and were therefore classified as 'possible heart disease', or, as in $\mathbf{3 1}$ cases $(13 \%)$, in spite of pathological evidence referable to heart disease, a definite diagnosis was not made. This latter group was called 'probable heart disease'.

No physical criterion could be found by which to distinguish an innocent murmur, either in relation to intensity, location, or continuity of the murmur. A thorough clinical examination, including relevant laboratory tests, electrocardiogram and fluoroscopy, is necessary in each case in order to arrive at the proper distinction. Even so, there is no warrant that a murmur, at first considered innocent, may not indicate a structural disposition to develop a serious heart condition at a later time.

\section{REFERENCES}

Blake, J. R. and Goodale, W. T. (1957). Med. Clin. N. Amer., 41, 1224

Epstein, N. (1948). J. Pediat., 32, 39.

Evans, W. (1947). Brit. Heart J., 9, 1.

Fogel, D. H. (1957). Pediatrics, 19, 793.

Katz, L. N. (1949).

Leopold, S. S. (1957). The Principles and Methods of Physical Diagnosis, 2nd ed., p. 308. Saunders, Philadelphia.

Lessof, M. and Brigden, W. (1957). Lancet, 2, 673.

Luisada, A. A. (1954). Heart, 2nd ed., p. 83. Williams and Wilkins,

Baltimore.
New York Heart Association (1955). Nomenclature and Criteria for Diagnosis of Diseases of the Heart and Blood Vessels, p. 26.

Pullen, R. L. (1945). Medical Diagnosis, p. 372. Saunders, London and Philadelphia.

Rhodes, P. H. (1955). Bull. Denver rheum. Fever diagn. Serv., 12, 69

Stuckey, D. (1955). Med. J. Aust., 2, 841.

Szabo, M. and Ross, L. (1957). Dapim Refuiim, 16, 134

Wagner, J. and Graham, G. R. (1957). Brit. Heart J., 19, 318.

Wells, B. (1957). Ihid., 19, 129. 